Subscriber access provided by University of Massachusetts Amherst Libraries

\title{
Article
}

\section{A Label-free Sandwich Imaging Ellipsometry Immunosensor for Serological Detection of Procalcitonin}

Yike Li, Wei Liu, Gang Jin, Yu Niu, Yiping Chen, and Meng-Xia Xie

Anal. Chem., Just Accepted Manuscript • DOI: 10.1021/acs.analchem.8b00888 • Publication Date (Web): 30 May 2018

Downloaded from http://pubs.acs.org on May 30, 2018

\section{Just Accepted}

"Just Accepted" manuscripts have been peer-reviewed and accepted for publication. They are posted online prior to technical editing, formatting for publication and author proofing. The American Chemical Society provides "Just Accepted" as a service to the research community to expedite the dissemination of scientific material as soon as possible after acceptance. "Just Accepted" manuscripts appear in full in PDF format accompanied by an HTML abstract. "Just Accepted" manuscripts have been fully peer reviewed, but should not be considered the official version of record. They are citable by the Digital Object Identifier (DOI®). "Just Accepted" is an optional service offered to authors. Therefore, the "Just Accepted" Web site may not include all articles that will be published in the journal. After a manuscript is technically edited and formatted, it will be removed from the "Just Accepted" Web site and published as an ASAP article. Note that technical editing may introduce minor changes to the manuscript text and/or graphics which could affect content, and all legal disclaimers and ethical guidelines that apply to the journal pertain. ACS cannot be held responsible for errors or consequences arising from the use of information contained in these "Just Accepted" manuscripts. 


\title{
A Label-free Sandwich Imaging Ellipsometry Immunosensor for Se- rological Detection of Procalcitonin
}

\author{
Yike $\mathrm{Li}^{\dagger}$, Wei $\mathrm{Liu}^{\ddagger}{ }^{\ddagger}$, Gang $\mathrm{Jin}^{\S, \perp}$, Yu Niu${ }^{*}, \S$, Yiping Chen ${ }^{*}$ ", Mengxia Xie ${ }^{*}$, \\ ${ }^{\dagger}$ Analytical \& Testing Center of Beijing Normal University, Beijing 100875, China. \\ ${ }^{\ddagger}$ Institute of Microelectronics, Tsinghua University, Beijing 100084, China. \\ ${ }^{\S}$ NML, Beijing Key Laboratory of Engineered Construction and Mechanobiology, Institute of Mechanics, Chinese Acade- \\ my of Sciences, Beijing 100190, China. \\ ${ }^{\perp}$ School of Engineering Science, University of Chinese Academy of Science, Beijing 100049, China. \\ "CAS Key Laboratory for Biological Effects of Nanomaterials and Nanosafety, CAS Key Laboratory of Standardization and \\ Measurement for Nanotechnology, CAS Center for Excellence in Nanoscience, National Center for Nanoscience and Tech- \\ nology, Beijing 100190, China.
}

E-mail: niuyu@imech.ac.cn (Y Niu), Phone number: (86)10 82544139

E-mail: cyp89@126.com (YP Chen), Phone number: (86)10 82545631

E-mail: xiemx@bnu.edu.cn (MX Xie), Phone number: (86)10 58807981

\begin{abstract}
Analysis of trace low molecular weight (LMW) proteins in serum using the label-free imaging ellipsometry (IE) immunosensor is still a challenge due to the lack of an effective signal amplification strategy and the serious non-specific adsorption. Herein we have developed a sandwich strategy-mediated IE (SSIE) immunosensor to enable the immunodetection of LMW protein biomarkers in serum samples. We have firstly found that the weak binding affinity and the insufficient surface amount density of the ligand are two important factors which hinder the detection of LMW proteins in serum using the IE immunosensor. Then we have deduced that the sandwich strategy can amplify the detection signal of IE and avoid the non-specific adsorption in serum. As a validation of the serological detection of LMW proteins, the SSIE immunosensor has been used to accomplish the quantitative detection of procalcitonin (PCT) in serum. Compared with other PCT analysis methodologies, the SSIE immunosensor enjoys the advantages of simplicity, rapidity, and sufficient sensitivity. Furthermore, we have proposed the criteria to predict the ability of the SSIE immunosensor for the detection of LMW protein biomarkers in serum, which can make the detection of LMW proteins smart and efficient.
\end{abstract}

Antibiotic misuse is a worldwide public health issue. The inappropriate use of antibiotics not only aggravates the antibiotic resistance, but also makes severe side effects on human health ${ }^{1}$. Thus, the accurate infection diagnosis before the antibiotic therapy is necessary in clinic. Procalcitonin (PCT), a polypeptide of 116 amino acids with the molecular weight of $13 \mathrm{kDa}$, is an FDA approved blood infection marker for guiding antibiotic therapy ${ }^{2}$. In clinic, the antibiotic therapy is highly recommended when PCT concentration in serum is over 0.5 ng $\mathrm{mL}^{-13}$. In addition, the serum PCT level also plays an advisory role in the sepsis diagnosis: over $2 \mathrm{ng} \mathrm{mL}^{-1}$ is suggestive of sepsis ${ }^{4}$. Therefore, it is of great importance to achieve the quantitative detection of PCT in serum.

Currently, several commercial kits ${ }^{5-7}$ and many labdeveloped assays ${ }^{8-10}$ have been used to detect PCT in serum. Some of them reach the impressive limit of detection (LOD). These methods mainly base on the introduction of labeling tags, which gives rise to high sensitivity but increases complexity and cost. A label-free alternative is preferable to provide the simple and rapid serological detection of PCT. How- ever, it is a challenge for label-free immunosensors to detect such low molecular weight (LMW) proteins with the molecular weight less than $25 \mathrm{kDa}^{5}$ as PCT in serum. The challenge comes from two aspects. On the one hand, the small parameter variation caused by the LMW proteins, for example the change of surface mass density, often approaches or even less than the resolution of the label-free immunosensors ${ }^{11,12}$, which requires amplification strategies to enhance the immunosensor response to the LMW proteins. The other challenge is the nonspecific adsorption from the serum ${ }^{13,14}$. Although many works have focused on developing anti-fouling immunosensor substrates ${ }^{15}$, the non-specific adsorption still haunts in practice and its interference cannot be eliminated completely in the serological detection ${ }^{13}$.

As a typical label-free immunosensor, the imaging ellipsometry (IE) immunosensor ${ }^{16}$ transforms the recognition of the biomolecules into the ellipsometry signal in image. By combining the ellipsometry with the microscopy, IE enjoys both a large field of view up to several square centimeters and a high vertical spatial resolution better than $0.1 \mathrm{~nm}^{17}$. There- 
fore, by sensitively visualizing the thickness change of the adsorption film that caused by the biomolecule interactions, the IE immunosensor with a microfluidic cell has the merits of simplicity, sensitivity, large throughput, and low sample consumption. Currently, it has acquired several applications in the epidemic diagnosis ${ }^{17,18}$. However, the detection of LMW proteins using the IE immunosensor also faces the same problems as other label-free immunosensors.

In this work, we have introduced and improved a sandwich strategy into IE immunosensor to enhance the sensitivity of conventional IE immunosensor and then successfully employed this sandwich strategy-mediated (SSIE) immunosensor for detection of PCT in serum samples. In this sandwich strategy, we employ detection antibody (dAb) to specifically recognize the LMW protein analyte and form the sandwich complex. This complex can greatly enhance the signal of IE immunosensor and eliminate the influence of the non-specific adsorption effectively. Therefore, the sensitivity of the SSIE has been greatly improved and meets the requirement to detect trace LMW proteins in complex samples. Scheme 1 illustrates the superiority of the SSIE immunosensor. As an application, we have carried out the serological immunodetection of PCT and systemically evaluated its analytical performance. To the best of our knowledge, it is the first report to effectively solve the problem for the IE immunosensor to detect LMW proteins in serum.

\section{EXPERIMENTAL SECTION}

\section{The IE immunosensor apparatus}

The IE immunosensor is mainly composed of a microfluidic microarray bioreactor and an imaging ellipsometer ${ }^{16,19}$. The microfluidic bioreactor fabricates a patterned protein microarray. It owns 48 independent flow channels and the volume of each channel is about $200 \mathrm{~nL}$, so the microfluidic bioreactor consumes only several $\mu \mathrm{L}$ of the analyte. The imaging ellipsometer can simultaneously capture the images of the fabricated protein microarray and visualize the thickness distribution of the protein layers in grayscale. The principle to detect protein interactions with the IE immunosensor is demonstrated in Figure $\mathrm{S} 1{ }^{18}$.

\section{Materials, reagents, and clinical samples}

Polished silicon wafers from General Research Institute for Nonferrous Metals (Beijing, China) are used for the substrate of the IE immunosensor. Monoclonal antibody to PCT as the capture antibody (cAb) is from Beijing Genstars Biotech Co., Ltd. (Beijing, China). Recombinant human PCT protein is purchased from Abcam (Cambridge, UK). Anti-PCT antibody as the $\mathrm{dAb}$ is bought from Invitrogen (Waltham, US). 3 -aminopropyltriethoxysilane, glutaraldehyde (50\% aqueous solution), human immunoglobulin (IgG), human serum albumin (HSA), C-reactive protein (CRP), carcinoembryonic antigen (CEA) and blocking buffer are purchased from SigmaAldrich (Missouri, USA). Phosphate buffered saline (PBS, $\mathrm{pH}$ 7.4) and PBST (containing $0.05 \%$ Tween-20) are prepared in deionized water produced by a Millipore Milli-Q ion exchange apparatus. The negative serum as well as 12 patient serum samples with detailed clinical background and ELECSYS PCT assay detection results are collected in Beijing Friendship Hospital (Beijing, China).

PCT detection procedure with the SSIE immunosensor
The surface modification procedure of silicon wafers as the IE immunosensor substrates is referred to our previous work ${ }^{20,21}$. To prepare the SSIE immunosensor, cAb is first immobilized on the modified silicon substrate covalently at 1 $\mu \mathrm{L} \mathrm{m^{-1 }}$ for $10 \mathrm{~min}$ followed by washing with PBST. Then the blocking buffer is injected at $1 \mu \mathrm{L} \mathrm{m^{-1 }}$ for $30 \mathrm{~min}$ to block the non-specific binding sites with the subsequent washing with PBST. For PCT detection by the SSIE immunosensor, PCT analyte solution is injected to react with $\mathrm{cAb}$ specifically at $2 \mu \mathrm{L} \mathrm{min}{ }^{-1}$ for $5 \mathrm{~min}$ and then rinsed with PBST for 1 min. After that, $\mathrm{dAb}$ is delivered at $1 \mu \mathrm{L} \mathrm{min}{ }^{-1}$ for $3 \mathrm{~min}$ followed by washing with PBST for $1 \mathrm{~min}$.

\section{Sensitivity, selectivity, and recovery study of PCT detec- tion}

The sensitivity study includes establishing the calibration curve and evaluating LOD. The calibration curve is performed under the optimized condition to detect PCT standard samples from 0.125 to $128 \mathrm{ng} \mathrm{mL}^{-1}$. The calibration curve is obtained by assaying each concentration at least 6 times. The calculation of LOD is based on the calibration curve with $\mathrm{S} / \mathrm{N}=3$, where $\mathrm{S}$ and $\mathrm{N}$ are the PCT detection signal and the standard deviation of 20 independent blank control measurements, respectively ${ }^{22}$. On the selectivity study, IgG, HSA, CRP, and CEA solution at $100 \mathrm{ng} \mathrm{mL}^{-1}$ is mixed with $10 \mathrm{ng} \mathrm{mL}^{-1}$ PCT and then tested with the SSIE immunosensor, respectively. Twice diluted negative serum is taken as the blank control. The recovery study is carried out by the standard addition method in which PCT at different concentrations $(0.5,2,4,8$, and $16 \mathrm{ng} \mathrm{mL}^{-1}$ ) are added to the twice diluted negative human serum samples.

\section{Clinical sample detection by the SSIE immunosensor}

12 PCT serum samples are collected from the people who may suffer bacterial infection in Beijing Friendship Hospital (China) in accordance with the rules of the local ethical committee. The serum samples are diluted twice with PBST and each sample is assayed at least 3 times. By correlation analysis and paired t-test, a double-blinded comparison of the results is accomplished between the SSIE immunosensor and the commercial ELECSYS PCT assay.

\section{RESULTS AND DISCUSSION}

\section{The IE immunosensor response to the ligand-analyte in- teraction}

To understand the limitations of the label-free IE immunosensor to detect the LMW proteins in serum, we have analyzed the factors influencing the response to the ligand-analyte interaction on the immunosensor substrate. Under the optimized azimuth settings of the polarizer and the analyzer (seeing the Supporting Information), the IE immunosensor responds approximately linearly to the thickness variation of the protein layer with a relative error less than $0.2 \%{ }^{23}$. Since the thickness of the protein layer is proportional to its surface mass density ${ }^{24}$, the relationship between the IE immunosensor signal, $\delta I$, and the surface mass density of the protein layer, $\delta \Gamma$, can be given by

$$
\delta I \propto \delta \Gamma=\delta \gamma \cdot M \#(1)
$$

where $\delta \gamma$ and $M$ are the surface amount density of the protein layer and the protein molecular weight, respectively.

For the direct IE immunosensor, a typical interaction between the ligand and the analyte on the substrate follows 


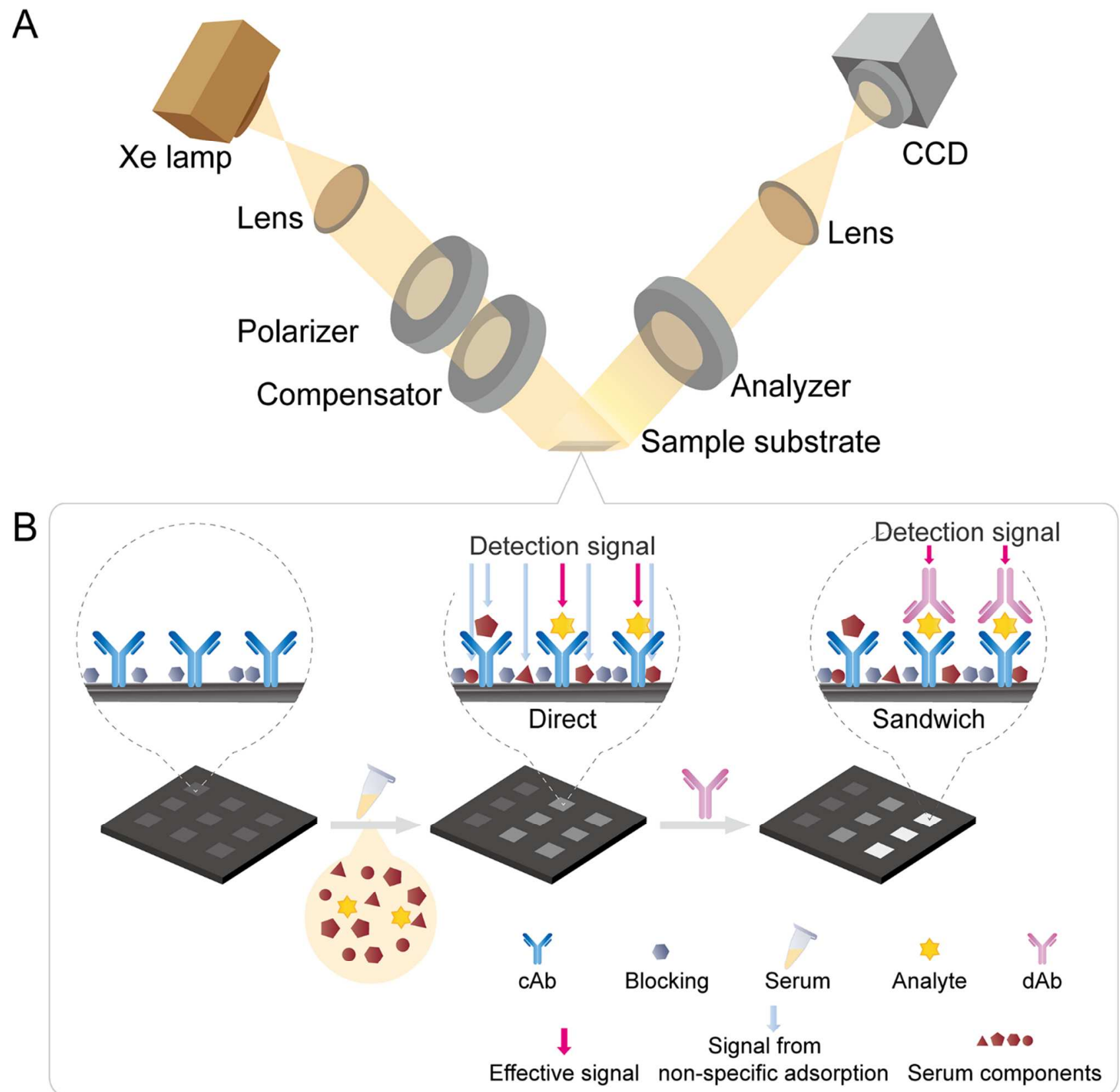

Scheme 1. The SSIE immunosensor for the detection of LMW proteins in serum. (A) The schematic of the label-free IE immunosensor with the typical conventional polarizer-compensator-sample-analyzer configuration. (B) The schematic of the SSIE immunosensor and its superiority to the direct IE immunosensor for the detection of LMW proteins in serum ${ }^{a}$.

${ }^{a}$ The capture antibody $(\mathrm{cAb})$ is immobilized on the substrate and then followed by the blocking treatment. The injection of the serum not only leads to the specific recognition between the $\mathrm{cAb}$ and the analyte, but also results in the non-specific adsorption. In the direct IE immunosensor, the non-specific adsorption brought by the serum is inevitable and might cause false-positive results. In the SSIE immunosensor, because the effective detection signal comes from dAb, its results are rarely affected by the non-specific adsorption.

ligand + analyte $\rightleftharpoons$ ligand $\cdot$ analyte. Under the pseudo first order interaction assumption ${ }^{25}$, the surface amount density change caused by the interaction, $\gamma_{\text {analyte }}$, can be expressed by (seeing the Supporting Information for the deduction)

$$
\gamma_{\text {analyte }}=\frac{\left(\gamma_{\text {ligand }}\right)_{0} \cdot c_{\text {analyte }}}{K_{D}+c_{\text {analyte }}} \#(2)
$$

where $\left(\gamma_{\text {ligand }}\right)_{0}, K_{D}$, and $c_{\text {analyte }}$ are the initial surface amount density of the ligand before the interaction, the dissociation equilibrium constant of the interaction, and the analyte concentration in the solution, respectively.
By equations (1) and (2), the relationship between the signal or surface mass density change of the direct IE immunosensor caused by the formation of the ligand analyte complex and the analyte concentration in solution is given by

$$
I_{\text {direct }} \propto \Gamma_{\text {analyte }}=\frac{\left(\gamma_{\text {ligand }}\right)_{0} \cdot c_{\text {analyte }}}{K_{D}+c_{\text {analyte }}} \cdot M_{\text {analyte }} \#(3)
$$

Besides $M_{\text {analyte }}$, equation (3) suggests that $\left(\gamma_{\text {ligand }}\right)_{0}$, $K_{D}$, and $c_{\text {analyte }}$ also exert significant impacts. For a given analyte at the specific concentration, $\left(\gamma_{\text {ligand }}\right)_{0}$ and $K_{D}$ are determinants of the improved $\Gamma_{\text {analyte }} \cdot\left(\gamma_{\text {ligand }}\right)_{0}$ stands for 
the effective amount of the ligand that can bind specifically to the analyte. The higher $\left(\gamma_{\text {ligand }}\right)_{0}$ implies more analyte can be recognized. However, too much ligand reduces its capability of recognizing the analyte because the spatial conformation change of the ligand diminishes the bioactivity and increases the steric hindrance on the immunosensor substrate. $K_{D}$ reflects the binding affinity of the interaction. The small $K_{D}$ suggests the strong binding affinity between the ligand and the analyte. Thus, a low $K_{D}$ leads to an improved $\Gamma_{\text {analyte }}$, enhancing the LOD of the analyte. However, too strong binding affinity also hinders the detection sensitivity because it blurs the distinctions among the analyte at the different concentrations. As a result, it is of great importance to choose a ligand with adequate $K_{D}$ and then optimize $\left(\gamma_{\text {ligand }}\right)_{0}$ for a better detection performance.

In the IE immunosensors, the antibody is commonly used as the ligand to detect the analytes. Thus, we need to choose the antibody with the optimized $K_{D}$ and $\left(\gamma_{\text {ligand }}\right)_{0}$. In our previous study, $\left(\gamma_{\text {ligand }}\right)_{0}$ of the saturated antibody layer is less than $4 \mathrm{pM} \mathrm{cm}^{-2}$. For the LMW analyte at the concentration of $0.5 \mathrm{ng} \mathrm{mL} \mathrm{L}^{-1}$, the cut-off value of PCT for bacterial infection diagnosis in clinic, Figure 1A gives the relationship among the ideal $\Gamma_{\text {analyte }}, M_{\text {analyte }}$, and typical $K_{D}$ according to equation (3). Since the thickness resolution of our IE immunosensor achieves $0.1 \mathrm{~nm}{ }^{18}$, the corresponding surface mass density resolution of a protein layer is better than $0.012 \mu \mathrm{g} \mathrm{cm}^{-2} 24$. As demonstrated in Figure 1A, $\Gamma_{\text {analyte }}$ is improved with the increase of the binding affinity (the decrease of $K_{D}$ ) or the molecular weight increase of the analyte. For the antibodies with $K_{D}$ at $10 \mathrm{nM}$ and $1 \mathrm{nM}, \Gamma_{\text {analyte }}$ remains less than the IE immunosensor resolution, indicating the protein analytes cannot be detected with the direct IE immunosensor. For the antibodies with higher affinity, $K_{D}$ approaching $100 \mathrm{pM}$ or less, $\Gamma_{\text {analyte }}$ exceeds the IE immunosensor resolution. However, it is still a challenge to detect LMW protein analytes by the direct IE immunosensor in practice because of the lack of the antibodies with such high binding affinity. The available $K_{D}$ of the commercial antibodies is about several $\mathrm{nM}^{26}$. In that case, an amplification strategy is needed for the detection of the LMW protein analytes.

\section{The design of the SSIE immunosensor to detect LMW pro- teins in serum}

As a simple and effective amplification strategy, the sandwich strategy is usually adopted to amplify the immunodetection response to the $\mathrm{LMW}$ protein over $5 \mathrm{kDa}$, since it requires the analyte with multiple epitopes to bind with two antibodies simultaneously ${ }^{27}$. The general process of the sandwich strategy has three steps: the $\mathrm{cAb}$ is first immobilized onto the substrate covalently, then the analyte is introduced to bind with the $\mathrm{cAb}$ specifically and finally $\mathrm{dAb}$ is added to form the $\mathrm{cAb} \cdot$ analyte$\cdot \mathrm{dAb}$ sandwich complex.

The surface mass density of the sandwich strategy, $\Gamma_{\text {sandwich }}$, is the sum of the analyte surface mass density, $\Gamma_{\text {analyte }}$, and the dAb surface mass density, $\Gamma_{d A b}$. Similar to equation (3), the relationship between the surface mass density of the sandwich strategy and the analyte concentration in solution is given by (seeing the Supporting Information for the deduction)

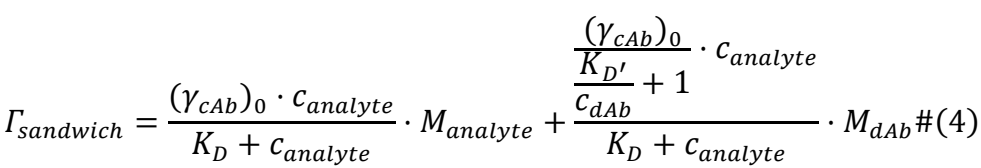

where $K_{D}$ and $K_{D^{\prime}}$ are the dissociation equilibrium constants of the interaction between $\mathrm{cAb}$ and the analyte, and the interaction between $\mathrm{dAb}$ and the analyte, respectively. $\left(\gamma_{c A b}\right)_{0}$ is the initial surface amount density of $\mathrm{cAb}$ on the immunosensor substrate. As dAb concentration, $c_{d A b}$, can be several magnitudes larger than $K_{D^{\prime}}$, making $K_{D^{\prime}} / c_{d A b}+1 \approx 1$, the equation (4) can be approximately expressed by

$I_{\text {sandwich }} \propto \Gamma_{\text {sandwich }} \approx \frac{\left(\gamma_{c A b}\right)_{0} \cdot c_{\text {analyte }}}{K_{D}+c_{\text {analyte }}} \cdot\left(M_{\text {analyte }}+M_{d A b}\right) \#$

Equation (5) demonstrates that the sandwich strategy translates the detection of the LMW analyte into the large analyte.dAb complex. Figure $1 \mathrm{~B}$ gives relationship among the ideal $\Gamma_{\text {sandwich }}, M_{\text {analyte }}$, and typical $K_{D}$ for the LMW protein analyte at $0.5 \mathrm{ng} \mathrm{mL}^{-1}$. Not only is $\Gamma_{\text {sandwich }}$ obviously larger than $\Gamma_{\text {analyte }}$, but the binding affinity requirement of the antibodies decreases nearly 2 magnitudes. For the antibodies with $K_{D}$ around $1 \mathrm{nM}, \Gamma_{\text {sandwich }}$ is beyond the IE immunosensor resolution. Since these antibodies are easily obtained by commercial products, the sandwich strategy is a simple method to detect LMW protein analytes in practice.

For the clinical analysis, the non-specific adsorption in serum causes the false-positive signal, so we have analyzed the non-specific adsorption influence from the serum in the sandwich strategy. With the addition of the serum, the specific binding between $\mathrm{cAb}$ and the analyte can increase the IE immunosensor signal, but the non-specific adsorption also involves in the process. On the contrary, the subsequent introduction of $\mathrm{dAb}$ amplifies the IE immunosensor signal but suffers little from the non-specific adsorption. By equation (3) and (5), the ratio between the IE immunosensor signal of $\mathrm{dAb}$ and that of the sandwich strategy can be estimated by

$$
\begin{gathered}
I_{d A b} \propto \Gamma_{d A b} \approx \frac{\left(\gamma_{c A b}\right)_{0} \cdot c_{\text {analyte }}}{K_{D_{1}}+c_{\text {analyte }}} \cdot M_{d A b} \\
\frac{I_{d A b}}{I_{\text {sandwich }}}=\frac{\Gamma_{d A b}}{\Gamma_{\text {sandwich }}} \approx \frac{M_{d A b}}{M_{d A b}+M_{\text {analyte }}} \#(6) \\
\frac{I_{d A b}}{I_{a}}=\frac{\Gamma_{d A b}}{\Gamma_{\text {analyte }}} \approx \frac{M_{d A b}}{M_{\text {analyte }}}
\end{gathered}
$$

For PCT detection by the sandwich strategy, $I_{d A b}$ is $92 \%$ of $I_{\text {sandwich }}$, but $I_{d A b}$ is hardly influenced by the non-specific adsorption. We improve the sandwich strategy by taking $I_{d A b}$ as the response instead of $I_{\text {sandwich }}$ to form the SSIE immunosensor. The signal of the SSIE immunosensor is still large enough for PCT detection and suffers little from the nonspecific adsorption of the serum. As the cut-off value of PCT in serum is $0.5 \mathrm{ng} \mathrm{mL}^{-1}$ for the bacterial infection, we have calculated the surface mass density change of PCT at the cutoff concentration by the direct IE immunosensor and the SSIE immunosensor. In the direct IE immunosensor, PCT detection can only be accomplished by the antibody with $K_{D}$ less than $100 \mathrm{pM}$, while it can be realized in SSIE immunosensor by the antibody with $K_{D}$ at the magnitude of $1 \mathrm{nM}$. Therefore, SSIE immunosensor can amplify the signal of PCT and eliminate the uncontrollable non-specific adsorption from the serum, further improving the serological detection of PCT. 

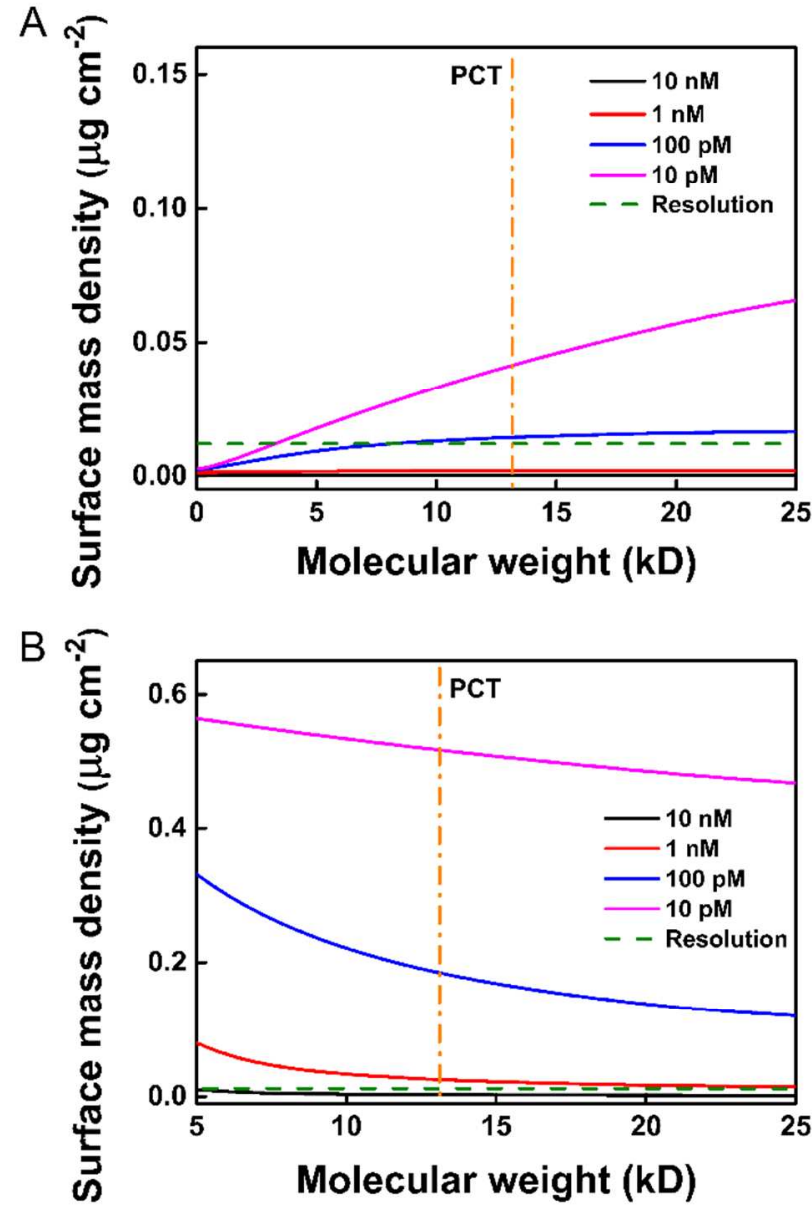

Figure 1. The surface mass density change caused by different molecular weight analytes at the concentration of $0.5 \mathrm{ng} \mathrm{mL}^{-1}$ on the saturated antibody adsorption substrate. (A) The direct IE immunosensor. (B) The SSIE immunosensor.

\section{Sensitivity, selectivity, and recovery study on PCT detec- tion}

We have optimized the $\mathrm{cAb}$ binding affinity, $\mathrm{cAb}$ concentration, and dAb detection time (Figure S2, S3 and S4). By equation (6), the binding affinity between $\mathrm{cAb}$ and PCT is the essential for the SSIE immunosensor signal. Among a series of commercial PCT antibodies from different companies, we have evaluated their binding affinity and chosen the antibody with the highest binding affinity as the $\mathrm{cAb}$ for PCT detection (Table S1 and Figure S2). Besides the binding affinity, the surface amount density of cAb also plays a key role in the SSIE immunosensor signal, so we have optimized the $\mathrm{cAb}$ concentration at $100 \mu \mathrm{g} \mathrm{mL}^{-1}$ (Figure S3). The dAb detection time has been optimized at 3 min (Figure S4). The sensitivity, selectivity, and recovery studies have been operated at the optimized conditions.

The sensitivity study is based on the establishment and analysis of the calibration curve. Figure $2 \mathrm{~A}$ is the typical grayscale image of the SSIE immunosensor for PCT quantitative detection from 0.125 to $128 \mathrm{mg} \mathrm{mL}^{-1}$. The SSIE immunosensor signal increases with the PCT concentration increasing. By equation (6), the calibration curve of the SSIE immunosensor is deduced as $I_{d A b}=51.820 \cdot c_{P C T} /\left(21.341+c_{P C T}\right)\left(R^{2}=\right.$ $0.997)$ in Figure $2 \mathrm{~B}$. As described in the Supporting Infor- mation, LOD is acquired as low as $0.081 \mathrm{ng} \mathrm{mL}^{-1}$ and the detection of PCT ranges from 0.125 to $128 \mathrm{ng} \mathrm{mL}^{-1}$. Since the cut-off value of PCT concentration in serum is $0.5 \mathrm{ng} \mathrm{mL}^{-1}$ and $2 \mathrm{ng} \mathrm{mL} L^{-1}$ for the antibiotic therapy and the sepsis in clinic, respectively, the PCT detection by the SSIE immunosensor meets the clinical requirements in sensitivity.

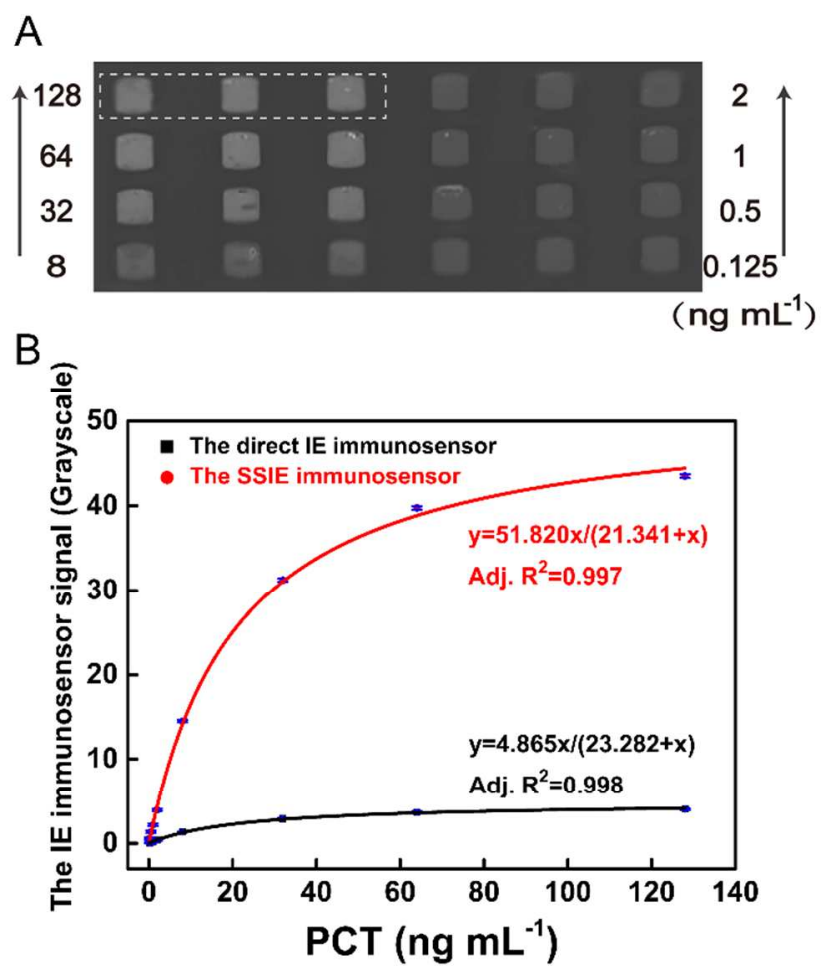

C

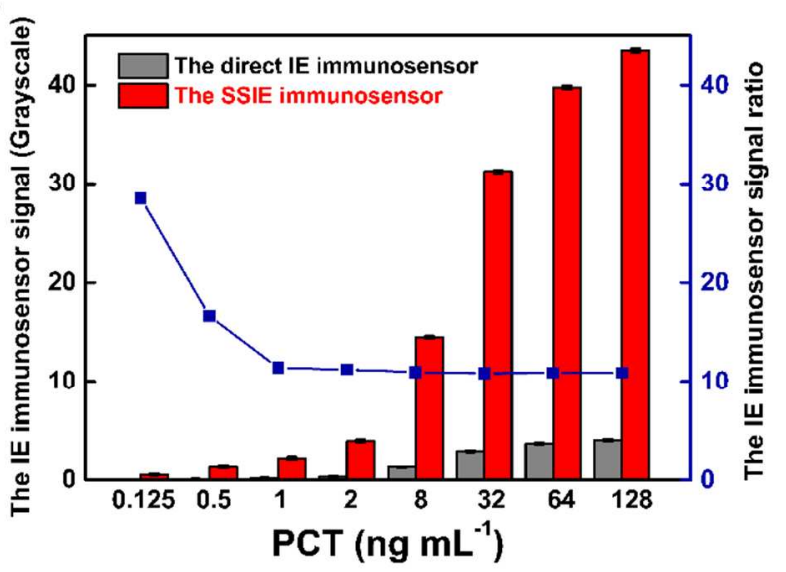

Figure 2. The sensitivity study of the SSIE immunosensor and the direct IE immunosensor for PCT detection. (A) The typical grayscale image of the SSIE immunosensor to establish the calibration curve for PCT quantitative detection. For each concentration three parallel data are recorded. (B) The calibration curve for PCT detection by the direct IE immunosensor and the SSIE immunosensor. (C) The comparison of PCT detection between the direct IE immunosensor and the SSIE immunosensor.

In order to evaluate the amplification efficiency of the SSIE immunosensor, we have compared the LOD and the sensitivity with those of the direct IE immunosensor (Figure $2 \mathrm{~B}$ and $2 \mathrm{C}$ ). The LOD of the SSIE immunosensor is $0.081 \mathrm{ng}$ $\mathrm{mL}^{-1}$, while that of the direct IE immunosensor is $0.973 \mathrm{ng}$ 
$\mathrm{mL}^{-1}$ according to its calibration curve $I_{\text {direct }}=4.865$. $c_{P C T} /\left(23.282+c_{P C T}\right)\left(R^{2}=0.998\right)$. Thus, the SSIE immunosensor improves the LOD about 12.0 times. On the other hand, by equation (6), the SSIE immunosensor signal should be as about $M_{d A b} / M_{P C T} \approx 11.5$ times as that of the direct IE immunosensor. For the PCT concentration over $0.973 \mathrm{ng} \mathrm{mL}{ }^{-1}$ as the LOD of the direct IE immunosensor, the ratio is in good agreement with the deduction. For PCT concentrations ranging from 0.125 to $128 \mathrm{ng} \mathrm{mL}^{-1}$, the signal change of SSIE immunosensor achieves about 42.93 grayscale, while that of the direct IE immunosensor responses to 3.97 grayscale, indicating that the SSIE immunosensor has better sensitivity. The results present the SSIE immunosensor can amplify PCT detection effectively and obtain the improved analytical performance.

Selectivity study can evaluate the anti-interference performance. We have chosen four proteins: IgG, HSA, CRP, and CEA as the interferents. IgG and HSA are the main protein fractions in serum. Like PCT, CRP is also one of the inflammatory markers in serum. CEA, as a common-used tumor marker in serum, has nearly the same molecular weight as PCT. Besides these four protein interferents, we have employed a negative human serum sample (tested and diagnosed by the hospital) as the blank control. In the selectivity test, PCT concentration is $10 \mathrm{ng} \mathrm{mL}^{-1}$, while the concentration of these interferents is $100 \mathrm{ng} \mathrm{mL}^{-1}$. As shown in Figure 3, the SSIE immunosensor signal of $10 \mathrm{ng} \mathrm{mL}^{-1}$ PCT with interferents is the same as that of $10 \mathrm{ng} \mathrm{mL}^{-1}$ PCT without interferents. For the samples with the interferents only, the SSIE immunosensor signal is similar to that of the blank control. The results demonstrate that the PCT detection by the SSIE immunosensor holds good selectivity.

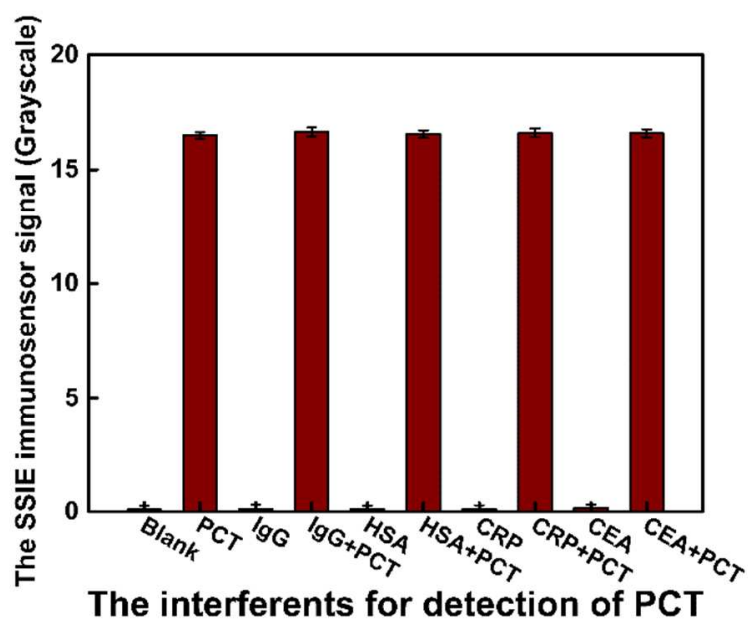

Figure 3. The selectivity study for the SSIE immunosensor. IgG, HSA, CRP, and CEA are used as the interferents to evaluate the selectivity, while the negative human serum is used as the blank control. The concentration of PCT is $10 \mathrm{ng} \mathrm{mL}^{-1}$, while the concentrations of IgG, HSA, CRP, and CEA are $100 \mathrm{ng} \mathrm{mL}^{-1}$, respectively.

Recovery study can estimate the accuracy and the reproducibility. Following the standard addition method, we have added PCT standard samples into the negative serum to form a series of PCT solutions at the concentrations of $0.5,2,4,8$, and $16 \mathrm{ng} \mathrm{mL}^{-1}$. As listed in Table 1 , the recovery rates range from $99.62 \%$ to $103.07 \%$ with coefficients of variation $(\mathrm{CV})$ below $15 \%$. The results show that the PCT detection by the SSIE immunosensor has good accuracy and reproducibility.

Table 1. Recovery study of the SSIE immunosensor in negative human serum $(\mathrm{N}=5)$

\begin{tabular}{cccc}
\hline $\begin{array}{c}\text { Added PCT } \\
\left(\mathrm{ng} \mathrm{mL}^{-1}\right)\end{array}$ & $\begin{array}{c}\text { Found PCT } \\
\left.(\mathrm{ng} \mathrm{mL})^{-1}\right)\end{array}$ & Recovery (\%) & CV (\%) \\
\hline 0.5 & 0.52 & 103.07 & 9.34 \\
2 & 2.03 & 101.44 & 2.23 \\
4 & 3.99 & 99.84 & 1.14 \\
8 & 8.02 & 100.29 & 1.20 \\
16 & 15.94 & 99.62 & 0.93 \\
\hline
\end{tabular}

Evaluating the non-specific adsorption of the SSIE immunosensor and clinical sample analysis

Human serum contains a large variety of proteins at a high concentration from 60 to $80 \mathrm{mg} \mathrm{mL}^{-115,28}$. These proteins cause the non-specific adsorption and change the surface mass density of the protein layer on the immunosensor substrate significantly, further resulting in the signal increase of the IE immunosensor and the incorrect clinical diagnosis. We have evaluated the SSIE immunosensor capability of preventing non-specific adsorption by using the negative serum in Figure 4A. Although the SSIE immunosensor is thoroughly blocked by the blocking buffer, with the addition of the negative serum, the significant increase of the immunosensor signal suggests the considerable non-specific adsorption. On the contrary, with the subsequent addition of $\mathrm{dAb}$, the stable signal demonstrates that little non-specific adsorption is involved. Thus, by taking the signal change caused by the addition of $\mathrm{dAb}$ as the response, the SSIE immunosensor presents good ability to avoid the non-specific adsorption in serum.

After twice dilution with the PBST buffer, 12 human serum samples have been tested by the SSIE immunosensor. The results are compared with those of the commercial ELECSYS PCT assay in Figure 4B. By correlation analysis and paired ttest, the SSIE immunosensor is proved to have good agreement with the commercial method. To further prove the necessity and advantage of the SSIE immunosensor which takes $I_{d A b}$ as the detection signal, we also have tested the same serum samples by the sandwich strategy with the IE immunosensor. The signal increase of the sandwich strategy $\left(I_{\text {sandwich }}\right)$ comes from the recognition of PCT $\left(I_{P C T}\right)$, the nonspecific adsorption from serum $\left(I_{\text {serum }}\right)$ and the amplification of $\mathrm{dAb}\left(I_{d A b}\right)$. The clinical analysis results can be divided into these three aspects in Figure 4C. $I_{\text {serum }}$ accounts for a significant proportion of $I_{\text {sandwich }}$, so the non-specific adsorption cannot be negligible. Besides, the large variety of $I_{\text {serum }}$ shows that the non-specific adsorption in serum samples is different from one another. Because $I_{\text {sandwich }}$ includes $I_{\text {serum }}$, it can be foreseen that the sandwich strategy would be suffered seriously from the non-specific adsorption. Likewise, we have compared the detection results of the sandwich strategy with the commercial method by correlation analysis and paired ttest. In Figure S5, the statistical analysis shows a significant difference between the sandwich strategy and the commercial method, indicating that the non-specific adsorption results in a rather poor detection accuracy. Since the SSIE immunosensor can eliminate influence of the non-specific adsorption effec- 
tively, it is a reliable and accurate method for the detection of PCT in clinical diagnosis.

A

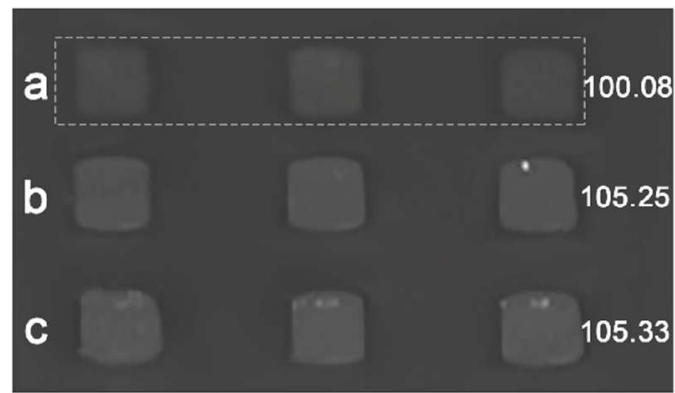

B
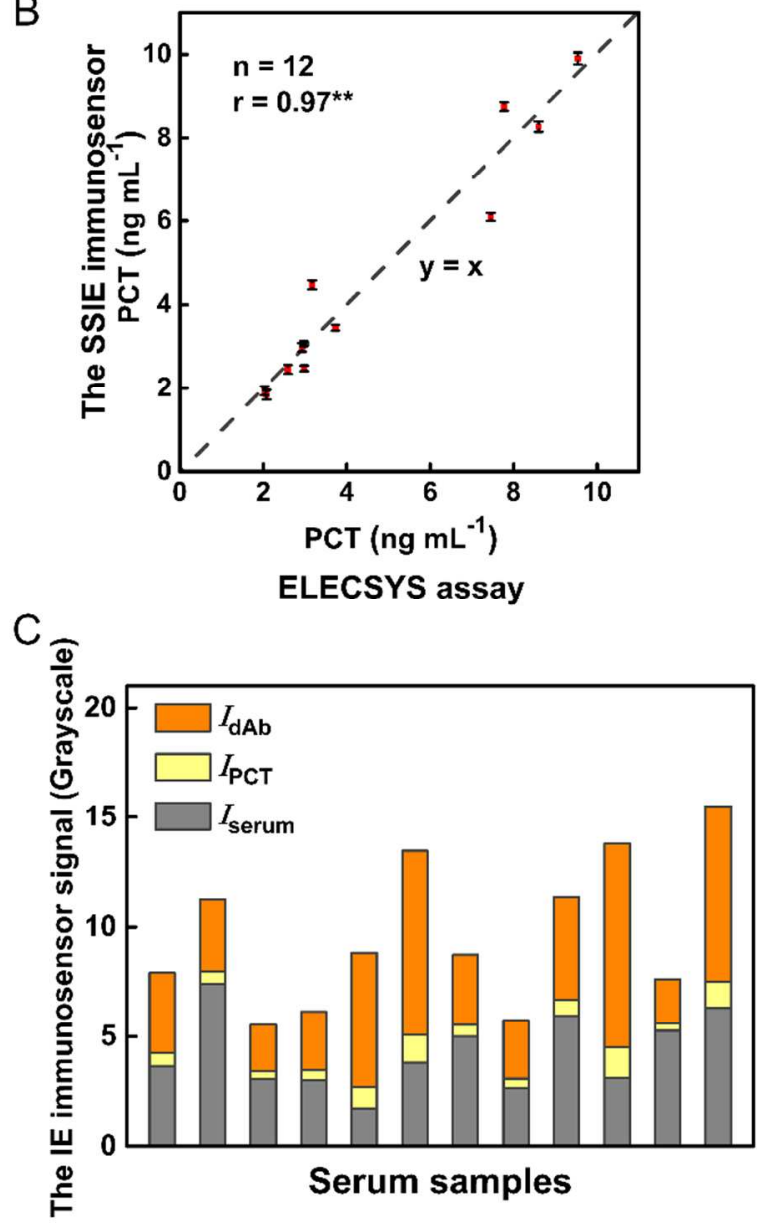

Figure 4. Evaluating the effect of non-specific adsorption to the SSIE immunosensor in clinical sample analysis. (A) Evaluation of the non-specific adsorption of the SSIE immunosensor from the negative serum. $\mathrm{cAb}$ is immobilized on the column $\mathrm{a}, \mathrm{b}$, and $\mathrm{c}$, and then followed by the blocking treatment. Twice-diluted negative serum is added to the column $\mathrm{b}$ and $\mathrm{c}$. $\mathrm{dAb}$ is subsequently delivered to the column $\mathrm{c}$. The average signals of the column $\mathrm{a}, \mathrm{b}$, and $\mathrm{c}$ are $100.08 \pm 0.10,105.25 \pm 0.07$, and $105.33 \pm 0.09$, respectively. (B) The comparison between the SSIE immunosensor and the commercial ELECSYS PCT assay for PCT detection in 12 human serum samples. ${ }^{* *}$ Correlation is significant at the 0.01 level (2-tailed). (C) Analysis of PCT detection results of $12 \mathrm{hu}$ man serum samples by sandwich strategy with the IE immunosensor. The signal of the sandwich strategy $\left(I_{\text {sandwich }}\right)$ is divided into the recognition of PCT $\left(I_{P C T}\right)$, the non-specific adsorption from serum $\left(I_{\text {serum }}\right)$ and the amplification of dAb $\left(I_{d A b}\right)$.
Comparison between the SSIE immunosensor and the current immunoassays for $\mathrm{PCT}$ detection

As PCT is a highly specific biomarker for bacterial infection and sepsis, its detection has attracted a lot of interest from the in-vitro diagnostics industry and the academic. Currently, commercial kits ${ }^{5-7}$ mainly depend on the original raw material from BRAHMS GmbH (Henningsdorf, Germany). Taking the ELECSYS PCT assay for example, it has good detection sensitivity at $0.060 \mathrm{ng} \mathrm{mL}^{-1}$ with short measurement time about $18 \mathrm{~min}$. However, all these commercial assays are based on the labelling technique, which brings high sensitivity but increases complexity and cost. Compared with the commercial immunoassays, many lab-developed methods ${ }^{8-10}$ have been applied for PCT detection and obtained overwhelming LOD

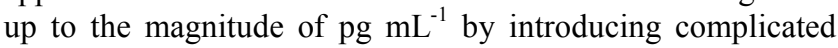
label tags, customized antibodies or even novel nanomaterials. These materials make the detection high-cost, time-consuming and labor-intensive.

We have overviewed the analytical performance of the SSIE immunosensor as well as these current methods for PCT detection in terms of the LOD, the detection range, the measurement time, and the sample consumption in Table 2. Compared with the current methods, the SSIE immunosensor not only meets the clinical requirements with the accessible commercial antibodies, but also has advantages in short measurement time and small sample consumption.

\section{The capability of the SSIE immunosensor for the detection of LMW protein biomarkers in serum}

To evaluate universality of the SSIE immunosensor as a general protocol for the serological detection of LMW proteins, we have deduced the relationship among $K_{D}$ of $\mathrm{cAb}$, the molecular weight, and the concentration of the analyte. The contour lines in Figure 5 indicate the detection performance of the SSIE immunosensor using cAb with typical $K_{D}$ values from 0.1 to $10 \mathrm{nM}$. The surface mass density at the lines is $0.012 \mu \mathrm{g} \mathrm{cm}^{-2}$, the SSIE immunosensor resolution. A point at the right area of the line means that its surface mass density exceeds the immunosensor resolution and is detectable with the corresponding $\mathrm{cAb}$. Thus, for a protein biomarker with the given cut-off value and the molecular weight, we can determine whether it can be detected by the SSIE immunosensor according to Figure 5, which is a smart protocol that can greatly improve the detection efficacy. We have remarked several common-used biomarkers for bacterial infection, cardiovascular disease, and oncogenesis ${ }^{29-31}$ in Figure 5. It demonstrates that the SSIE immunosensor has the capability of detecting most of the LMW protein biomarkers in serum, greatly broadening the applications of the conventional IE immunosensor. 
Table 2. The comparison of the analytical performance between the SSIE immunosensor and the current methods for PCT detection

\begin{tabular}{|c|c|c|c|c|c|}
\hline Name/Method & $\begin{array}{l}\text { LOD } \\
\left(\mathrm{ng} \mathrm{mL} L^{-1}\right)\end{array}$ & $\begin{array}{l}\text { Detection } \\
\text { Range } \\
\left(\mathrm{ng} \mathrm{mL} \mathrm{m}^{-1}\right)\end{array}$ & $\begin{array}{l}\text { Measurement } \\
\text { Time }\end{array}$ & $\begin{array}{l}\text { Sample Con- } \\
\text { sumption } \\
(\mu \mathrm{L})\end{array}$ & Reference \\
\hline Kryptor (Brahms) & 0.060 & $0.020-50$ & $19 \mathrm{~min}$ & 100 & 5 \\
\hline $\begin{array}{l}\text { ADVIA Centaur CP } \\
\text { (Brahms/Siemens) }\end{array}$ & 0.050 & $0.020-75$ & $26 \mathrm{~min}$ & 100 & 6 \\
\hline $\begin{array}{l}\text { ELECSYS } \\
\text { (Brahms/Roche) }\end{array}$ & 0.060 & $0.020-100$ & $18 \mathrm{~min}$ & 30 & 7 \\
\hline MIS & 0.044 & $0.025-128$ & $<2 \mathrm{~h}$ & 50 & 10 \\
\hline $\begin{array}{l}\text { Electrochemical immu- } \\
\text { noassay }\end{array}$ & 0.001 & $0.010-350$ & $>8 \mathrm{~h}$ & 50 & 8 \\
\hline Total Internal Reflection & 0.040 & $0.025-10$ & $9 \min$ & 50 & 9 \\
\hline The SSIE immunosensor & 0.081 & $0.125-128$ & $10 \mathrm{~min}$ & 10 & This work \\
\hline
\end{tabular}

ASSOCIATED CONTENT

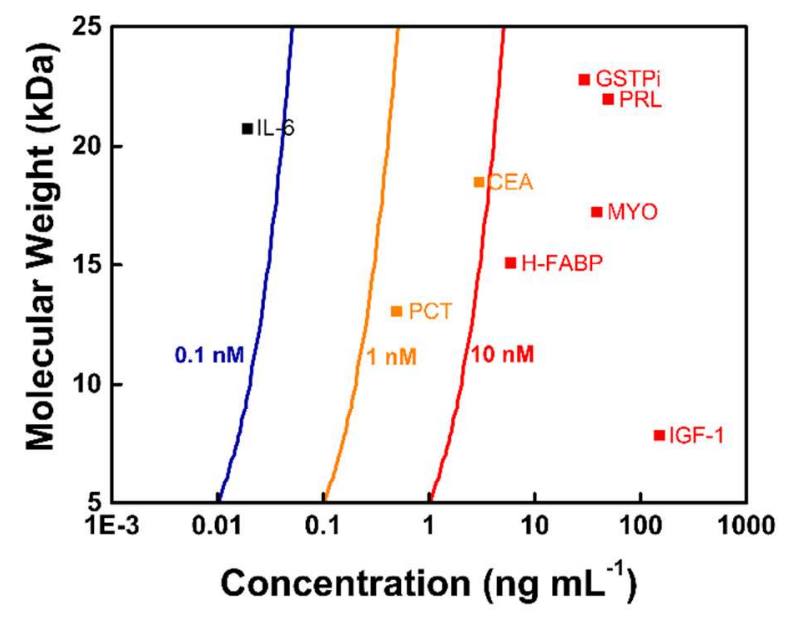

Figure 5. The contour map for the detection of biomarkers by the SSIE immunosensor. $\mathrm{X}$-axis and $\mathrm{Y}$-axis are the concentration and the molecular weight of the analyte, respectively. The contour line demonstrates the change of the surface mass density at $0.012 \mu \mathrm{g}$ $\mathrm{cm}^{-2}$ using $\mathrm{cAb}$ with typical $K_{D}$. Common-used biomarkers such as CEA, glutathione S transferases Pi (GSTPi), heart-type fatty acid binding protein (H-FABP), insulin-like growth factor 1 (IGF1), interleukin 6 (IL-6), myoglobin (MYO), PCT, and prolactin (PRL) are marked in the contour map.

\section{CONCLUSION}

In summary, we have systematically analyzed the factors that affect the signal of the IE immunosensor and constructed the SSIE immunosensor for the detection of LWM proteins. With the SSIE immunosensor, we have accomplished the serological detection of PCT with good analytical performance. This straightforward SSIE immunosensor can not only amplify the response to LMW proteins but avoid the non-specific adsorption from the serum, promoting the IE immunosensor as an excellent label-free platform for detecting trace LMW protein biomarkers for clinical purpose. Furthermore, the SSIE immunosensor is a smart protocol that owns a predicative ability, which can greatly improve detection efficiency and reduce cost. We will focus on developing a portable and completely automatic IE immunosensor in the future work.

\section{Supporting Information}

Introduction and detection principle of the IE immunosensor (Figure S1)

Deduction of the relationship between the IE immunosensor signal and the analyte concentration

Optimization of experimental conditions (Table S1, Figure S2-S4) Determining the limit of detection

Comparison between the IE immunosensor (using $I_{\text {sandwich }}$ as the detection signal) and the commercial ELECSYS PCT assay (Figure S5)

\section{AUTHOR INFORMATION}

\section{Corresponding Author}

*Yu Niu: E-mail: niuyu@imech.ac.cn.

* Yiping Chen: E-mail: cyp89@126.com.

* Mengxia Xie: E-mail: xiemx@bnu.edu.cn.

\section{ORCID}

Yu Niu: 0000-0003-2380-1006

Yiping Chen: 0000-0002-8399-763X

\section{Notes}

The authors declare no competing financial interest.

\section{ACKNOWLEDGMENT}

The authors thank the financial support to the International Science \& Technology Cooperation Program of China (2015DFG32390), to the National Basic Research Program of China (2015CB352100), to the National Natural Science Foundation of China (11704218, 81472941, 21305147, and 81671784), and to the Youth Innovation Promotion Association of the Chinese Academy of Sciences (2017026).

\section{REFERENCES}

(1) Bouadma, L.; Luyt, C.-E.; Tubach, F.; Cracco, C.; Alvarez, A.; Schwebel, C.; Schortgen, F.; Lasocki, S.; Veber, B.; Dehoux, M.; Bernard, M.; Pasquet, B.; Régnier, B.; Brun-Buisson, C.; Chastre, J.; Wolff, M. Use of procalcitonin to reduce patients' exposure to 
antibiotics in intensive care units (PRORATA trial): a multicentre randomised controlled trial. Lancet 2010, 375, 463-474.

(2) Schuetz, P.; Wirz, Y.; Sager, R.; Christ-Crain, M.; Stolz, D.; Tamm, M.; Bouadma, L.; Luyt, C. E.; Wolff, M.; Chastre, J.; Tubach, F.; Kristoffersen, K. B.; Burkhardt, O.; Welte, T.; Schroeder, S.; Nobre, V.; Wei, L.; Bucher, H. C.; Annane, D.; Reinhart, K., et al. Effect of procalcitonin-guided antibiotic treatment on mortality in acute respiratory infections: a patient level meta-analysis. Lancet Infect. Dis. 2018, 18, 95-107.

(3) Tang, B. M. P.; Eslick, G. D.; Craig, J. C.; McLean, A. S. Accuracy of procalcitonin for sepsis diagnosis in critically ill patients: systematic review and meta-analysis. Lancet Infect. Dis. 2007, 7, 210217.

(4) Schneider, H.-G.; Thanh Lam, Q. Procalcitonin for the clinical laboratory: a review. Pathology 2007, 39, 383-390.

(5) Schuetz, P.; Christ-Crain, M.; Huber, A. R.; Müller, B. Long-term stability of procalcitonin in frozen samples and comparison of Kryptor ${ }^{\circledR}$ and VIDAS ${ }^{\circledR}$ automated immunoassays. Clin. Biochem. 2010, 43, 341-344.

(6) Dipalo, M.; Guido, L.; Micca, G.; Pittalis, S.; Locatelli, M.; Motta, A.; Bianchi, V.; Callegari, T.; Aloe, R.; Da Rin, G.; Lippi, G. Multicenter comparison of automated procalcitonin immunoassays. Practical Laboratory Medicine 2015, 2, 22-28.

(7) de Wolf, H. K.; Gunnewiek, J. K.; Berk, Y.; van den Ouweland, J.; de Metz, M. Comparison of a New Procalcitonin Assay from Roche with the Established Method on the Brahms Kryptor. Clin. Chem. 2009, 55, 1043-1044.

(8) Liu, F.; Xiang, G.; Yuan, R.; Chen, X.; Luo, F.; Jiang, D.; Huang, $\mathrm{S}$.; Li, Y.; Pu, X. Procalcitonin sensitive detection based on graphenegold nanocomposite film sensor platform and single-walled carbon nanohorns/hollow $\mathrm{Pt}$ chains complex as signal tags. Biosens. Bioelectron. 2014, 60, 210-217.

(9) Rascher, D.; Geerlof, A.; Kremmer, E.; Krämer, P.; Schmid, M.; Hartmann, A.; Rieger, M. Total internal reflection (TIRF)-based quantification of procalcitonin for sepsis diagnosis - A point-of-care testing application. Biosens. Bioelectron. 2014, 59, 251-258.

(10) Wu, J.; Chen, Y.; Yang, M.; Wang, Y.; Zhang, C.; Yang, M.; Sun, J.; Xie, M.; Jiang, X. Streptavidin-biotin-peroxidase nanocomplex-amplified microfluidics immunoassays for simultaneous detection of inflammatory biomarkers. Anal. Chim. Acta 2017, 982, 138-147.

(11) Feng, C.; Dai, S.; Wang, L. Optical aptasensors for quantitative detection of small biomolecules: A review. Biosens. Bioelectron. 2014, 59, 64-74.

(12) Ribaut, C.; Voisin, V.; Malachovská, V.; Dubois, V.; Mégret, P.; Wattiez, R.; Caucheteur, C. Small biomolecule immunosensing with plasmonic optical fiber grating sensor. Biosens. Bioelectron. 2016, 77, 315-322.

(13) Breault-Turcot, J.; Chaurand, P.; Masson, J.-F. Unravelling Nonspecific Adsorption of Complex Protein Mixture on Surfaces with SPR and MS. Anal. Chem. 2014, 86, 9612-9619.

(14) Schön, P.; Görlich, M.; Coenen, M. J. J.; Heus, H. A.; Speller, S. Nonspecific Protein Adsorption at the Single Molecule Level Studied by Atomic Force Microscopy. Langmuir 2007, 23, 9921-9923.

(15) Blaszykowski, C.; Sheikh, S.; Thompson, M. A survey of stateof-the-art surface chemistries to minimize fouling from human and animal biofluids. Biomater. Sci. 2015, 3, 1335-1370.

(16) Wang, Z.; Jin, G. A Label-Free Multisensing Immunosensor Based on Imaging Ellipsometry. Anal. Chem. 2003, 75, 6119-6123.

(17) Niu, Y.; Jin, G. Protein microarray biosensors based on imaging ellipsometry techniques and their applications. Protein Cell 2011, 2, 445-455.

(18) Jin, G. Development of biosensor based on imaging ellipsometry. Physica status solidi (A) 2008, 205, 810-816.
(19) Wang, Z.; Meng, Y.; Ying, P.; Qi, C.; Jin, G. A label - free protein microfluidic array for parallel immunoassays. Electrophoresis 2006, 27, 4078-4085.

(20) Wang, Z.; Jin, G. Covalent immobilization of proteins for the biosensor based on imaging ellipsometry. J. Immunol. Methods 2004, 285, 237-243.

(21) Huang, C.; Yang, Q.; Song, F.; Chen, N.; Liao, X.; Yao, B.; Zhang, S.; Chen, Y.; Jin, G. Site-directed immobilization antibody for alpha-fetoprotein detection by optical biosensor. Integr. Ferroelectr. 2016, 171, 70-78.

(22) Lu, J.; Spasic, D.; Delport, F.; Van Stappen, T.; Detrez, I.; Daems, D.; Vermeire, S.; Gils, A.; Lammertyn, J. Immunoassay for Detection of Infliximab in Whole Blood Using a Fiber-Optic Surface Plasmon Resonance Biosensor. Anal. Chem. 2017, 89, 3664-3671.

(23) Chen, Y.; Meng, Y.; Jin, G. Optimization of off-null ellipsometry for air / solid interfaces. Appl. Opt. 2007, 46, 8475-8481.

(24) Arwin, H.; Welin-Klintström, S.; Jansson, R. Off-Null Ellipsometry Revisited: Basic Considerations for Measuring Surface Concentrations at Solid/Liquid Interfaces. J. Colloid Interface Sci. 1993, 156, 377-382.

(25) Vijayendran, R. A.; Ligler, F. S.; Leckband, D. E. A Computational Reaction-Diffusion Model for the Analysis of Transport-Limited Kinetics. Anal. Chem. 1999, 71, 5405-5412.

(26) Landry, J. P.; Fei, Y. Y.; Zhu, X. D. Simultaneous Measurement of 10,000 Protein-Ligand Affinity Constants Using Microarray-Based Kinetic Constant Assays. Assay Drug Dev. Technol. 2012, 10, 250259.

(27) Shankaran, D. R.; Gobi, K. V.; Miura, N. Recent advancements in surface plasmon resonance immunosensors for detection of small molecules of biomedical, food and environmental interest. Sens. Actuators B-Chem. 2007, 121, 158-177.

(28) Strasser, S.; Niegelhell, K.; Kaschowitz, M.; Markus, S.; Kargl, R.; Stana-Kleinschek, K.; Slugovc, C.; Mohan, T.; Spirk, S. Exploring Nonspecific Protein Adsorption on Lignocellulosic Amphiphilic Bicomponent Films. Biomacromolecules 2016, 17, 1083-1092.

(29) Sturgeon, C. M.; Duffy, M. J.; Stenman, U.-H.; Lilja, H.; Brünner, N.; Chan, D. W.; Babaian, R.; Bast, R. C.; Dowell, B.; Esteva, F. J.; Haglund, C.; Harbeck, N.; Hayes, D. F.; HoltenAndersen, M.; Klee, G. G.; Lamerz, R.; Looijenga, L. H.; Molina, R.; Nielsen, H. J.; Rittenhouse, H., et al. National Academy of Clinical Biochemistry Laboratory Medicine Practice Guidelines for Use of Tumor Markers in Testicular, Prostate, Colorectal, Breast, and Ovarian Cancers. Clin. Chem. 2008, 54, e11-e79.

(30) Wu, J.; Fu, Z.; Yan, F.; Ju, H. Biomedical and clinical applications of immunoassays and immunosensors for tumor markers. Trac-Trends Anal. Chem. 2007, 26, 679-688.

(31) Braunwald, E. Biomarkers in Heart Failure. New Engl. J. Med. 2008, 358, 2148-2159. 
Table of Contents Graphic (For TOC only)

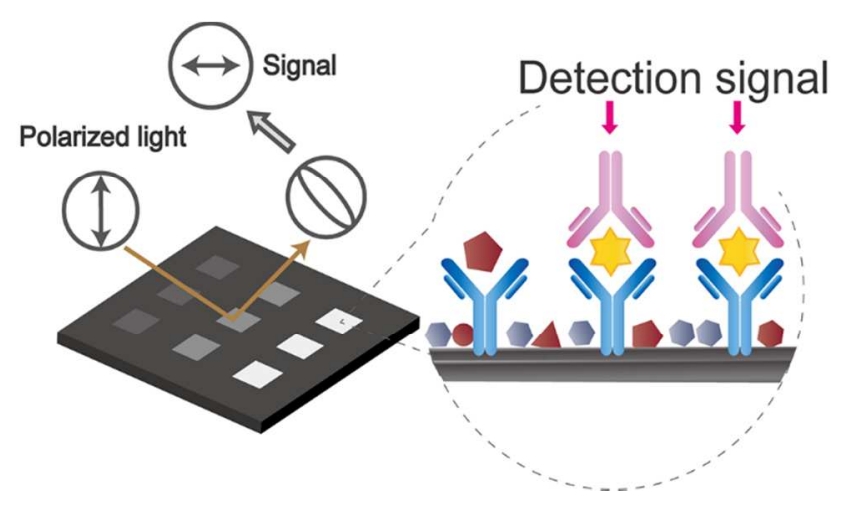


A
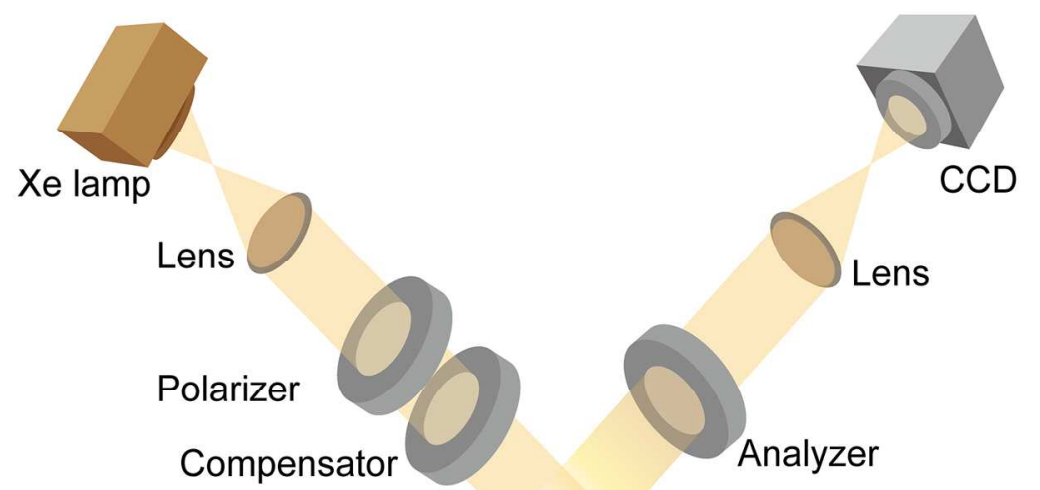

Xe lamp

Lens

\section{Polarizer}

Compensator

\section{Analyzer}

\section{Sample substrate}

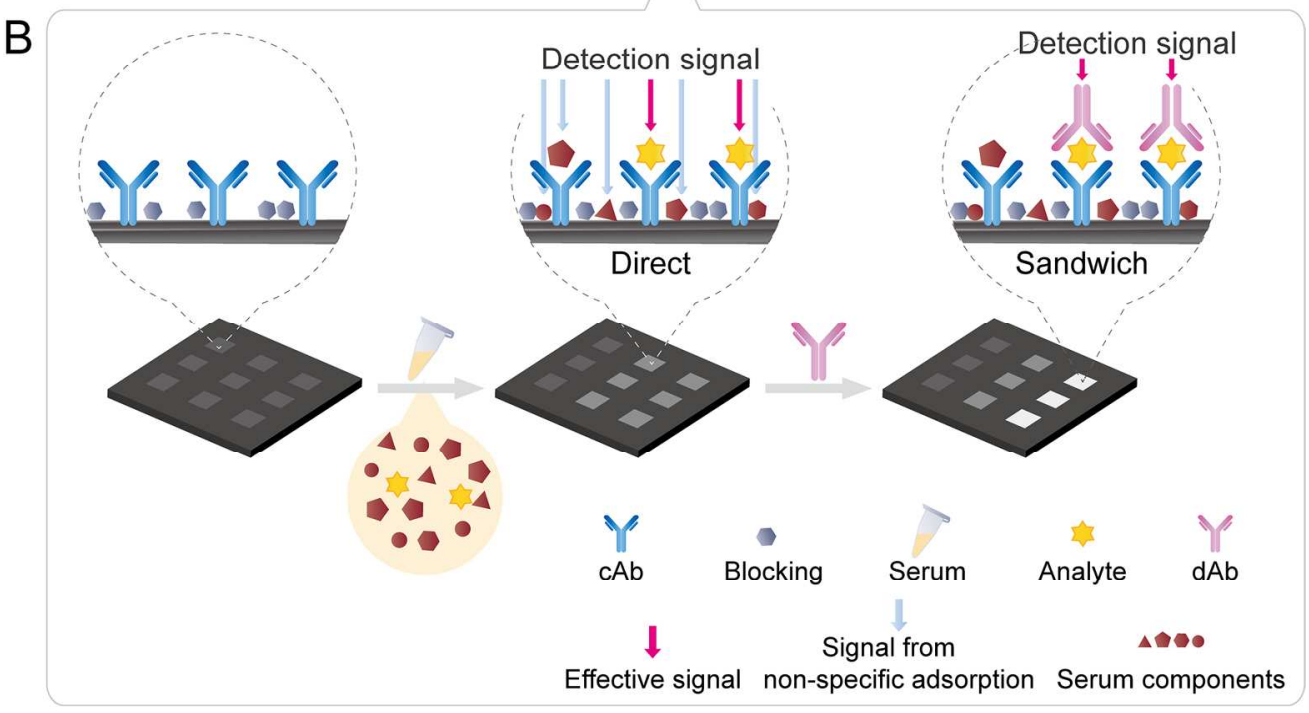

Scheme 1

$170 \times 167 \mathrm{~mm}(300 \times 300 \mathrm{DPI})$ 

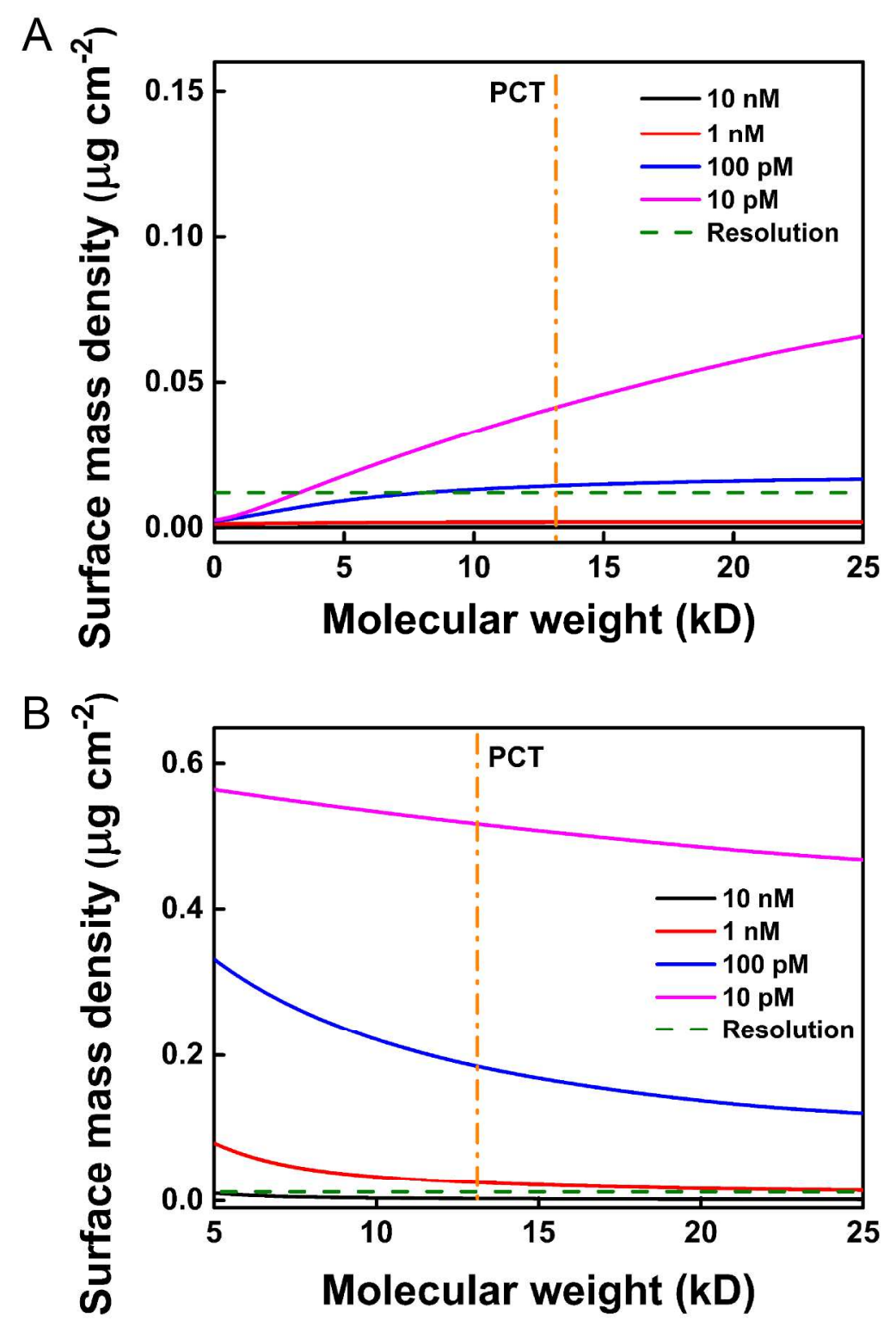

Figure 1

$125 \times 188 \mathrm{~mm}(600 \times 600 \mathrm{DPI})$ 

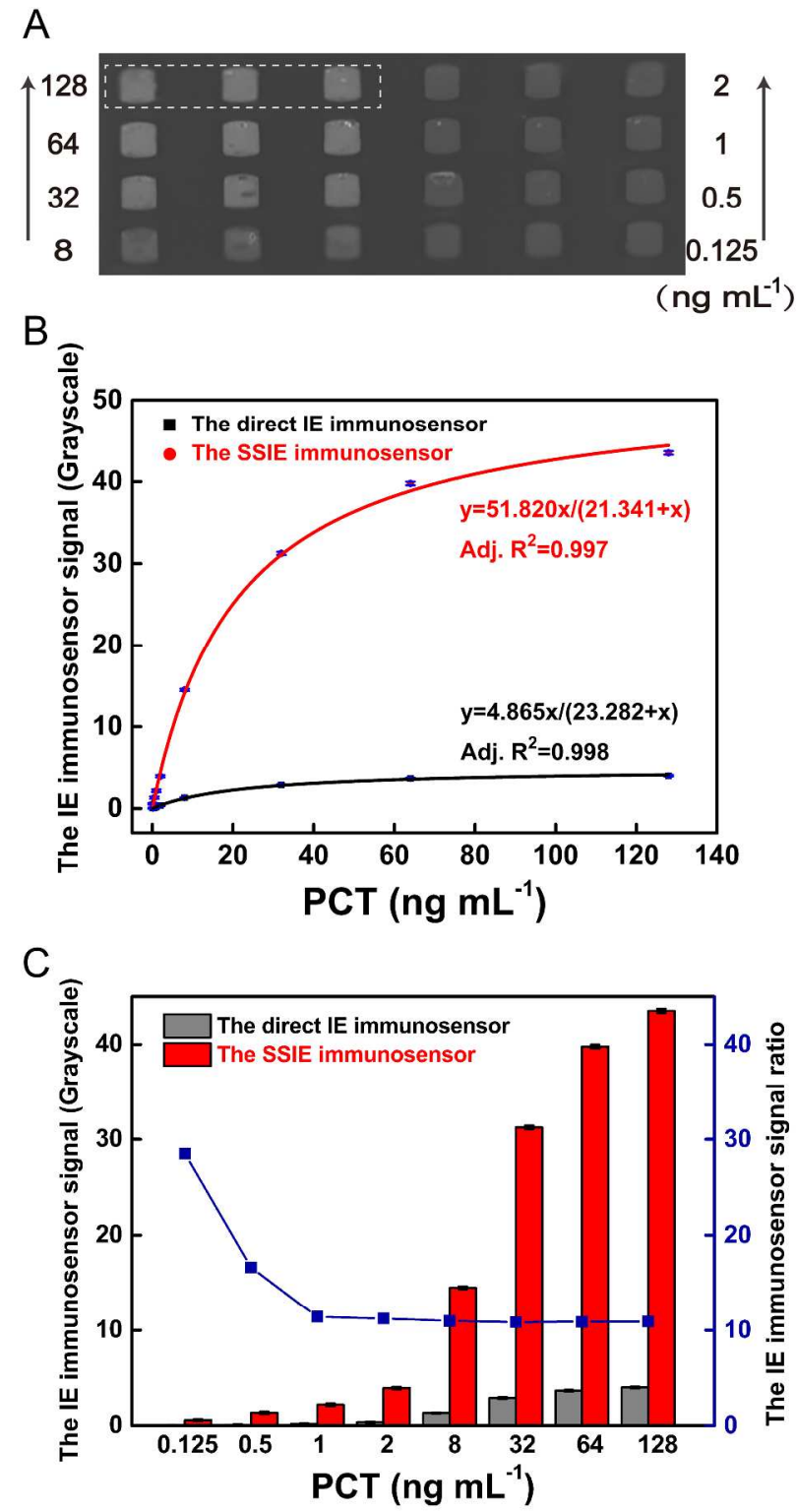

Figure 2

$161 \times 312 \mathrm{~mm}(600 \times 600$ DPI $)$ 


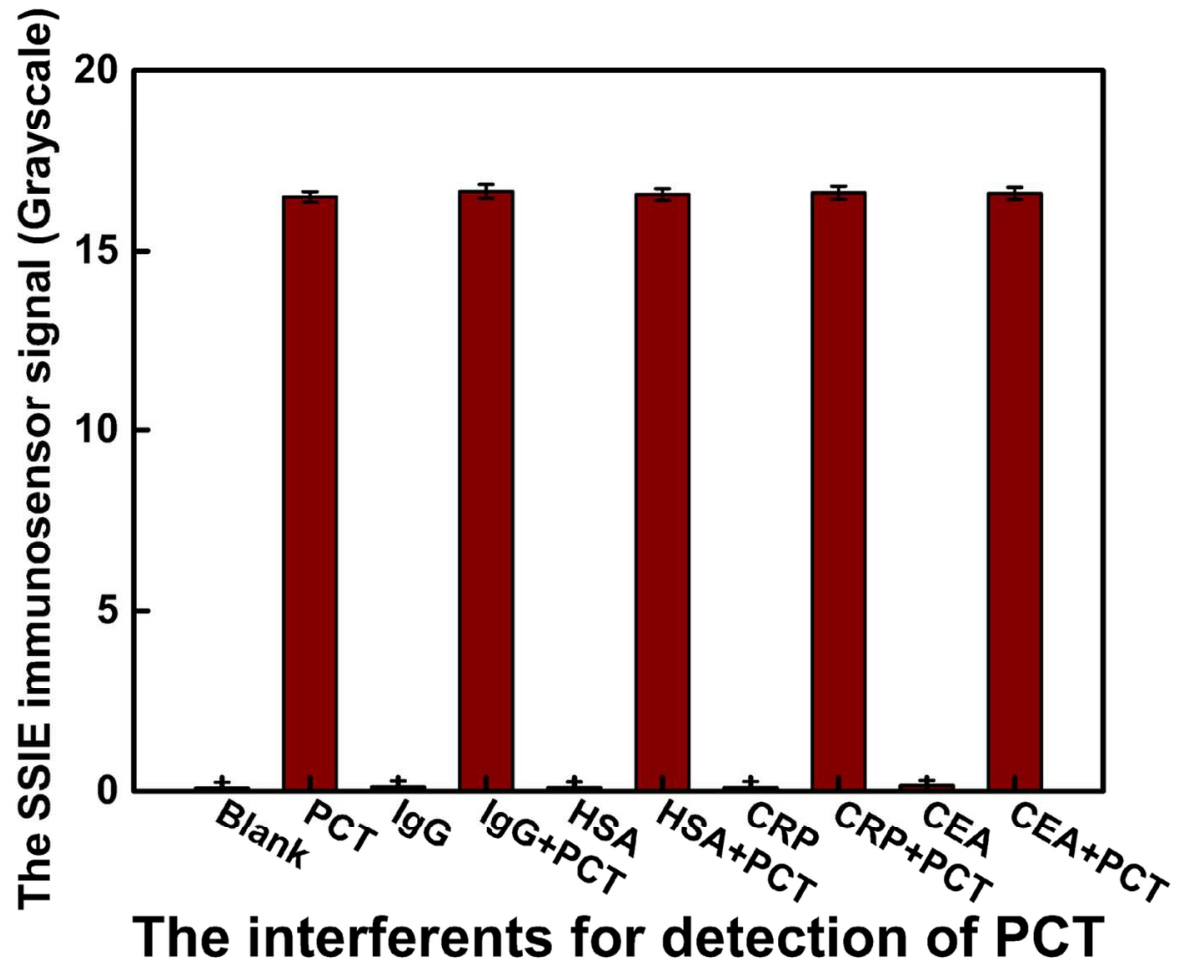

Figure 3

$62 \times 47 \mathrm{~mm}(600 \times 600 \mathrm{DPI})$ 


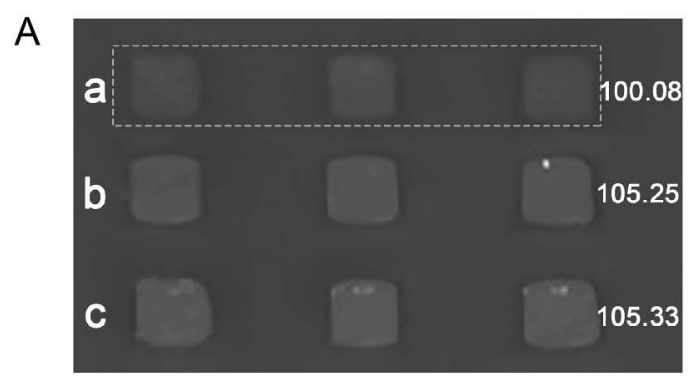

B
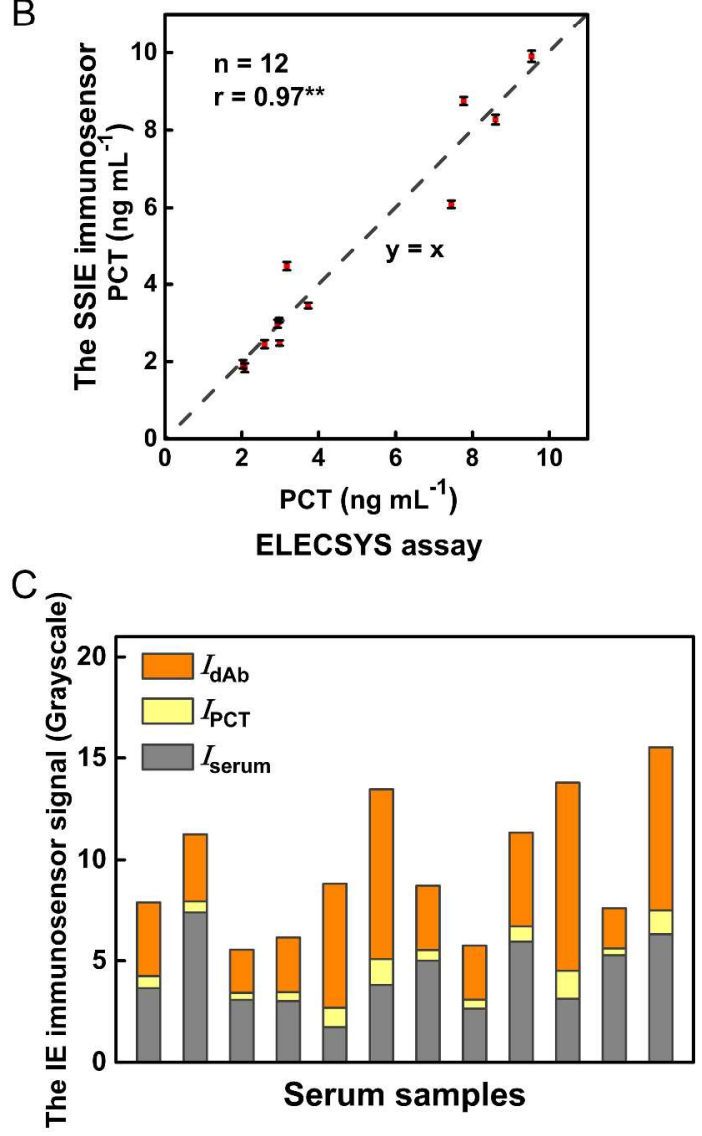

Figure 4

$171 \times 352 \mathrm{~mm}(600 \times 600 \mathrm{DPI})$ 


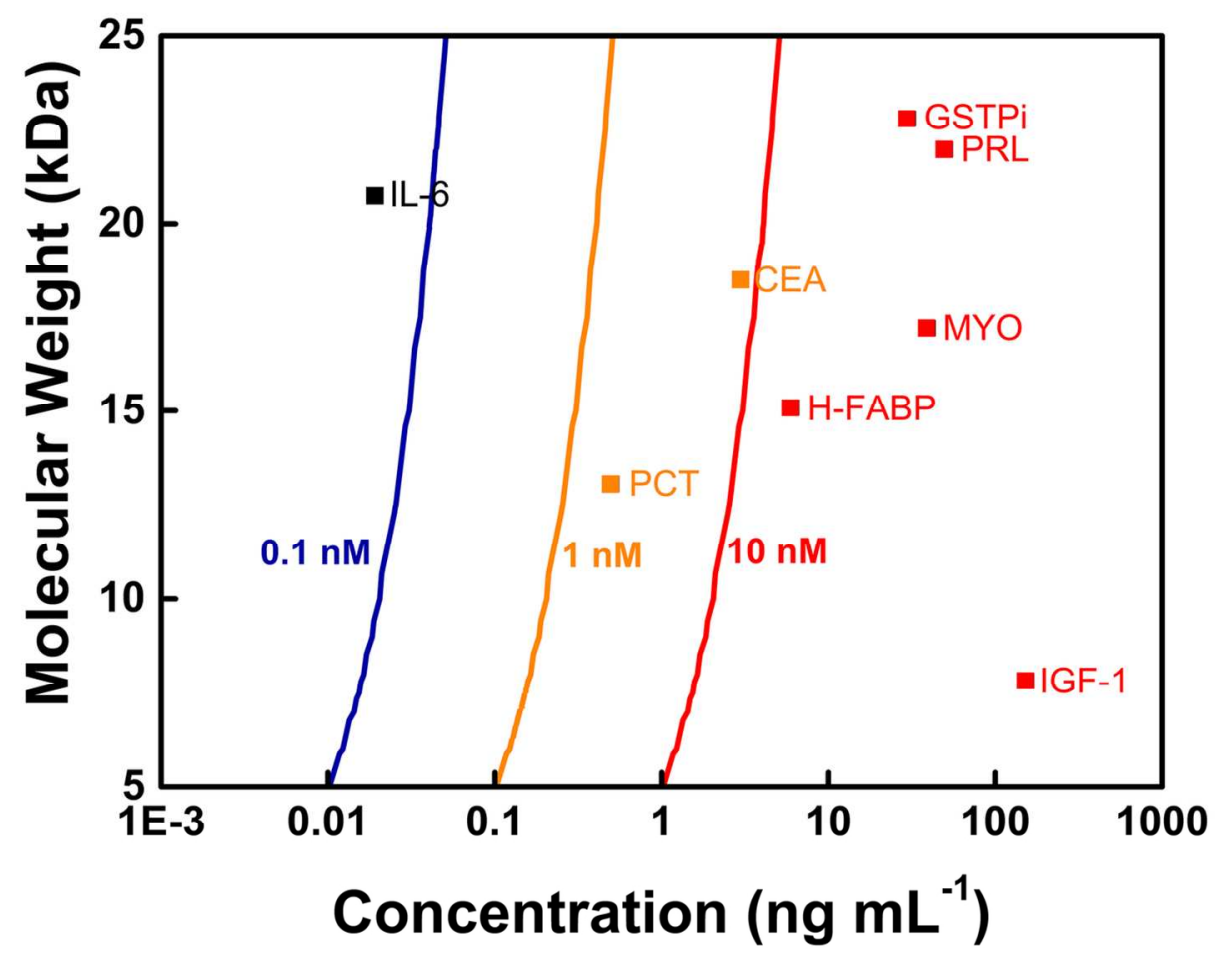

Figure 5

$62 \times 47 \mathrm{~mm}(600 \times 600 \mathrm{DPI})$ 


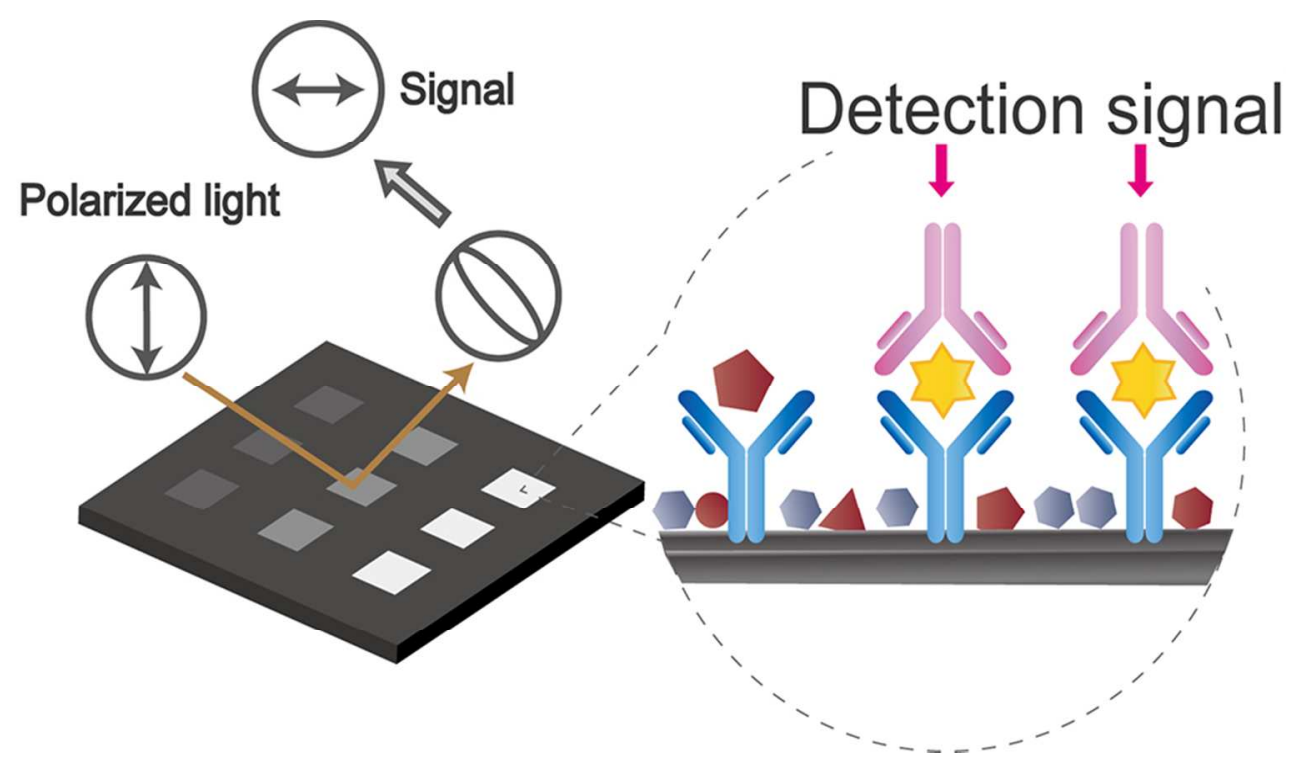

Table of Contents Graphic

$84 \times 47 m m(300 \times 300$ DPI $)$ 